\title{
Synthesis and spectral characterization of homo- and hetero-dinuclear complexes with a new septadentate Schiff base ligand
}

\author{
J K NAG, D DAS ${ }^{\mathrm{a}}$, S PAL and C SINHA* \\ Department of Chemistry, University of Burdwan, Burdwan 713 104, India \\ ${ }^{a}$ Department of Chemistry, TDB College, Raniganj 713 347, India \\ e-mail: bdnuvlib@giasc101.vsnl.net.in
}

MS received 1 June 2000; revised 2 September 2000

\begin{abstract}
Reaction between 3-formylsalicylic acid and bis-(2-aminophenyl)disulphide yields a septadentate Schiff base with $\mathrm{N}_{2} \mathrm{SO}_{4}$ donor frame of which the inner compartment is $\mathrm{N}_{2} \mathrm{SO}_{2}$ and the outer is $\mathrm{O}_{2} \mathrm{O}_{2}$ type. It forms several complexes with inner copper centre and outer nontransition/transition metal ions. The complexes have been characterised by elemental analyses, spectral (IR, absorption, diffused reflectance), thermal and magnetic data. Dinuclear copper complexes exhibit subnormal magnetic moments $(\approx 0.80 \mathrm{BM})$, showing magnetic exchange, and six-line solid-state ESR spectra at $77 \mathrm{~K}$.
\end{abstract}

Keywords. Septadentate Schiff base; copper complexes; compartmental ligand; subnormal magnetic moment; spectral characterization; ESR spectra.

\section{Introduction}

The chemistry of multimetallic species has grown steadily because of their involvement in the area of homogeneous catalysis, magnetic exchange between paramagnetic centres, optically induced intrasystem charge transfer and bioinorganic chemistry ${ }^{1-13}$. The potential of the field can be gauged from the appearance of many reviews in the literature ${ }^{1-3}$. Considerable effort has thus been directed towards the synthesis of ligands that can generate polynuclear systems, particularly capable of holding two similar or dissimilar metal ions, subject to control by appropriate modification of the molecular topology ${ }^{1-7}$. The ligands are predominantly Schiff bases, popularly known as compartmental or polypodal ligands. The Schiff bases derived from 3-formylsalicylic acid (FSA) and diamines act as binucleating side-off acyclic ligands ${ }^{9-14}$. The compartment size and the number of donor centres are fully monitored by the use of diamines. Bis-(2-aminophenyl)disulphide is a potential diamine for synthesising the $\mathrm{N}_{2} \mathrm{SO}_{4}$ donor frame with FSA in which one compartment is a Schiff base of the $\mathrm{N}_{2} \mathrm{SO}_{2}$ type, whose chemistry is well-known ${ }^{15,16}$ and the other compartment may be compared with keto-carboxylic acid and is designated $\mathrm{O}_{2} \mathrm{O}_{2}$ type. The subsequent metal incorporation may provide the opportunity to study the chemistry of binucleating systems. In this work, we report the synthesis of dinuclear stable, magnetically

*For correspondence 
interacting metal complexes derived from acyclic chelators incorporating thioether function.

\section{Experimental}

$\mathrm{UO}_{2}(\mathrm{OAc})_{2} \cdot 2 \mathrm{H}_{2} \mathrm{O}, \mathrm{Cu}_{2}(\mathrm{OAc})_{4} \cdot 2 \mathrm{H}_{2} \mathrm{O}$ were $\mathrm{BDH}$ reagents. All other chemicals used were of AR grade and were used as received. Solvents were purified by reported procedure ${ }^{17}$. 3-Formylsalicylic acid (FSA) ${ }^{18}$ and bis-(2-aminophenyl)disulfide ${ }^{16}$ were prepared according to literature procedure. $\left[\mathrm{Bu}_{4} \mathrm{~N}\right]\left[\mathrm{ClO}_{4}\right]$ and $\mathrm{MeCN}$ for electrochemical work were synthesised and purified by a previously described process ${ }^{19}$.

Microanalysis (C, H, N) were performed using a Perkin-Elmer $2400 \mathrm{CHN}$ elemental analyser and copper analysis was carried out by iodometric titration method ${ }^{20}$. Spectroscopic measurements were carried out using the following instruments: IR spectra, JASCO FT-IR model 420; UV-VIS spectra, Shimadzu UV-160A; diffused reflectance spectra, Hitachi U-3501 UV-VIS-NIR spectrophotometer; and ${ }^{1} \mathrm{H}-\mathrm{NMR}$, Brucker $200 \mathrm{MHz}$ FT-NMR spectrometers. Molar conductances $\left(\Lambda_{\mathrm{M}}\right)$ were measured in a Systronics conductivity meter 304 model using $\approx 10^{-3} \mathrm{M}$ solutions in DMF. Thermoanalytical data were obtained using Shimadzu TG 50/DT 50. Bulk magnetic moments $(\mu, \mathrm{BM})$ were obtained from vibrating sample magnetometer PAR 155 model. Electrochemical measurements were made with a computer-controlled PAR model 270 VERSTAT electrochemical instrument using a glassy carbon disk working electrode. All measurements were made at $298 \mathrm{~K}$ and were referenced to the saturated calomel electrode $(\mathrm{SCE})$ in DMF-MeCN with $\left[\mathrm{Bu}_{4} \mathrm{~N}\right]\left[\mathrm{ClO}_{4}\right]$ as a supporting electrolyte. The reported potentials are uncorrected for junction potential. ESR spectra were recorded at X-band on a Varian E-109C spectrometer. DPPH $(g=2.0037)$ was used to calibrate the spectra.

\subsection{Preparation of the ligand $\left(H_{4} L\right)$}

To a stirred methanolic solution (15 ml) of 3-formylsalicylic acid $(0 \cdot 35 \mathrm{~g}, 2.11 \mathrm{mM})$ was added bis-(2-aminophenyl)disulphide $(0.25 \mathrm{~g}, 1.01 \mathrm{mM})$ in the same solvent $(10 \mathrm{ml})$ dropwise and stirred for $1 \mathrm{~h}$ at room temperature. The yellow solid formed was filtered, washed with cold $\mathrm{MeOH}$-water $(1: 1, v / v, 5 \mathrm{ml} \times 2)$ and dried in vacuo. Yield, $0.4 \mathrm{~g}$ (70\%). MP $232 \pm 1^{\circ} \mathrm{C}$.

\subsection{Preparation of the complexes}

2.2a Preparation of $\left[\mathrm{Cu} \cdot \mathrm{H}_{2} \mathrm{O}\right] \mathrm{Na}_{2} \mathrm{~L} \cdot \mathrm{H}_{2} \mathrm{O}(\mathbf{1})$ : A solution $(30 \mathrm{ml})$ of $\mathrm{H}_{4} \mathrm{~L}(0 \cdot 55 \mathrm{~g}, 1 \cdot 01$ $\mathrm{mM})$ was added dropwise to a hot methanol solution $(25 \mathrm{ml})$ of $\mathrm{Cu}_{2}(\mathrm{OAc})_{4} \cdot 2 \mathrm{H}_{2} \mathrm{O}(0 \cdot 2 \mathrm{~g}$. $0.50 \mathrm{mM})$ in the presence of $\mathrm{NaOH}(0.18 \mathrm{~g}, 4.5 \mathrm{mM})$. The resulting mixture was refluxed for $4 \mathrm{~h}$ on a steam bath. The brown precipitate that formed was filtered hot and washed with methanol, ether and dried in vacuo. Yield, $0.44 \mathrm{~g} \mathrm{(64 \% ).}$

2.2b Preparation of $\left[\mathrm{Cu} \cdot \mathrm{H}_{2} \mathrm{O}\right] \mathrm{ML} \cdot n \mathrm{H}_{2} \mathrm{O}(\mathrm{M}=\mathrm{Ca}(\mathrm{II})$ (2), $\mathrm{Ba}(\mathrm{II})(3), \mathrm{Zn}(\mathrm{II})$ (4), $n=1$; $\left.M=U O_{2}(V I)(5)\right): \mathrm{Cu}_{2}(\mathrm{OAc})_{4} \cdot 2 \mathrm{H}_{2} \mathrm{O}(0.11 \mathrm{~g}, 0.28 \mathrm{mM})$ in $\mathrm{MeOH}(10 \mathrm{ml})$ was added dropwise to a methanol solution $(50 \mathrm{ml})$ of $\mathrm{H}_{4} \mathrm{~L}(0.3 \mathrm{~g}, 0.55 \mathrm{mM})$ in presence of $\mathrm{LiOH}$ $(0.06 \mathrm{~g}, 2.5 \mathrm{mM})$, and refluxed over a steam bath for $2 \mathrm{~h}$. A solution of $\mathrm{MCl}_{2}+2 \mathrm{NaOAc}$ 
$(\mathrm{M}=\mathrm{Ca}, \mathrm{Ba}) / \mathrm{Zn}(\mathrm{OAc})_{2} / \mathrm{UO}_{2}(\mathrm{OAc})_{2} \cdot 2 \mathrm{H}_{2} \mathrm{O}$ (one equivalent) in $\mathrm{MeOH}(20 \mathrm{ml})$ was added to the suspension and refluxed for an additional $4 \mathrm{~h}$. The dark precipitate that formed was filtered from the solution and washed with hot methanol $(5 \mathrm{ml} \times 4)$. The product was dried over $\mathrm{CaCl}_{2}$. Yield, 60-70\%.

2.2c Preparation of $\mathrm{Cu}_{2} \mathrm{~L} \cdot \mathrm{H}_{2} \mathrm{O}(\mathbf{6}): \mathrm{Cu}_{2}(\mathrm{OAc})_{4} \cdot 2 \mathrm{H}_{2} \mathrm{O}(0.22 \mathrm{~g}, 0.56 \mathrm{mM})$ in $\mathrm{MeOH}$ $(10 \mathrm{ml})$ was added dropwise to a methanol solution $(20 \mathrm{ml})$ of $\mathrm{H}_{4} \mathrm{~L}(0.3 \mathrm{~g}, 0.55 \mathrm{mM})$ in presence of $\mathrm{LiOH}(0.06 \mathrm{~g}, 2.5 \mathrm{mM})$, and refluxed over a steam bath for $2 \mathrm{~h}$. The dark coloured precipitate was filtered and washed with hot methanol $(5 \mathrm{ml} \times 4)$. The product was dried over $\mathrm{CaCl}_{2}$. Yield, $0 \cdot 31 \mathrm{~g}(82 \%)$.

2.2d Preparation of $\left(\mathrm{UO}_{2}\right)_{2} \mathrm{~L} \cdot \mathrm{H}_{2} \mathrm{O}$ (7): $\mathrm{UO}_{2}(\mathrm{OAc})_{2} \cdot 6 \mathrm{H}_{2} \mathrm{O}(0.48 \mathrm{~g}, 1.13 \mathrm{mM})$ was dissolved in $\mathrm{MeOH}(20 \mathrm{ml})$ and added dropwise to the methanolic solution $(25 \mathrm{ml})$ of $\mathrm{H}_{4} \mathrm{~L}(0.3 \mathrm{~g}, 0.55 \mathrm{mM})$. The mixture was refluxed for $2 \mathrm{~h}$ over steam bath. The product was filtered at hot and washed with hot methanol. It was then dried over $\mathrm{CaCl}_{2}$. Yield, $0.42 \mathrm{~g}(70 \%)$.

2.2e Preparation of $[\mathrm{Cu} \cdot \mathrm{S}]\left(\mathrm{UO}_{2}\right) \mathrm{L}(\mathrm{S}=\mathrm{Py}(\mathbf{8}), \quad \mathrm{DMSO}(\mathbf{9})):\left[\mathrm{Cu} \cdot \mathrm{H}_{2} \mathrm{O}\right]\left(\mathrm{UO}_{2}\right) \mathrm{L} \cdot \mathrm{H}_{2} \mathrm{O}$ $(0.01 \mathrm{mM})$ was suspended in the solvent, $\mathrm{S}$, and stirred for $8 \mathrm{~h}$ and then filtered. The filtrate was allowed to diffuse into $\mathrm{MeOH}$ upon layering for a week. Crystals formed were isolated and dried over $\mathrm{CaCl}_{2}$. Yield, $40-50 \%$.

\section{Results and discussion}

\subsection{Synthesis}

The ligand $\left(\mathrm{H}_{4} \mathrm{~L}\right)$ is obtained as a condensation product of bis-(2-aminophenyl)disulphide and 3-formylsalicylic acid (FSA) and has eight donor sites $\mathrm{N}_{2} \mathrm{~S}_{2} \mathrm{O}_{4}$. It acts however as a septadentate side-off ligand using two imine nitrogens, two phenolato oxygens, one disulphide sulphur and two carboxylato oxygens as donor sites. Thioether is not a good ligand to bind class of metal ions ${ }^{21}$ and in this ligand it is located in an internal position within the complexing side chains. This has been specifically designed in order that the chelation by $\mathrm{N}$ and $\mathrm{O}$ enforces $\mathrm{S}$ coordination ${ }^{15}$. The ligand has two compartments; one resembles Schiff base $\mathrm{N}_{2} \mathrm{SO}_{2}$ type and the second site is $\mathrm{O}_{2} \mathrm{O}_{2}$ type.

The complexes were synthesised by direct reaction between pure isolated ligand $\left(\mathrm{H}_{4} \mathrm{~L}\right)$ and metal acetates in $\mathrm{MeOH}$ in presence of $\mathrm{LiOH} / \mathrm{NaOH}$ with stoichiometric mole proportion to yield mono or dinuclear complexes. The complexes are listed in table 1 and their proposed structures are given in scheme 1. Hetero-dinuclear complexes with inner copper(II) core are $\left[\mathrm{Cu} \cdot \mathrm{H}_{2} \mathrm{O}\right] \mathrm{ML} \cdot \mathrm{H}_{2} \mathrm{O}\left(\mathrm{M}=\mathrm{Ca}\right.$ (II) (2), $\mathrm{Ba}$ (II) (3), $\mathrm{Zn}$ (II) (4), $\mathrm{UO}_{2}$ (VI) (5)) $\left(\left[\mathrm{Cu} \cdot \mathrm{H}_{2} \mathrm{O}\right]\right.$ refers to the inner core metallated fragment). They were synthesised from $\mathbf{1}$ and the second metal salt in 1:1 mole proportion.

The composition of the complexes are supported from the elemental analyses. The molar conductances $\left(\Lambda_{\mathrm{M}}\right)$ were measured in DMF; the complex $\mathbf{1}$ shows conductivity $120 \Omega^{-1} \mathrm{~cm}^{2} \mathrm{M}^{-1}$ at $25^{\circ} \mathrm{C}$ and is $1: 2$ electrolyte in nature. All other complexes remain almost insoluble and are not measured. 


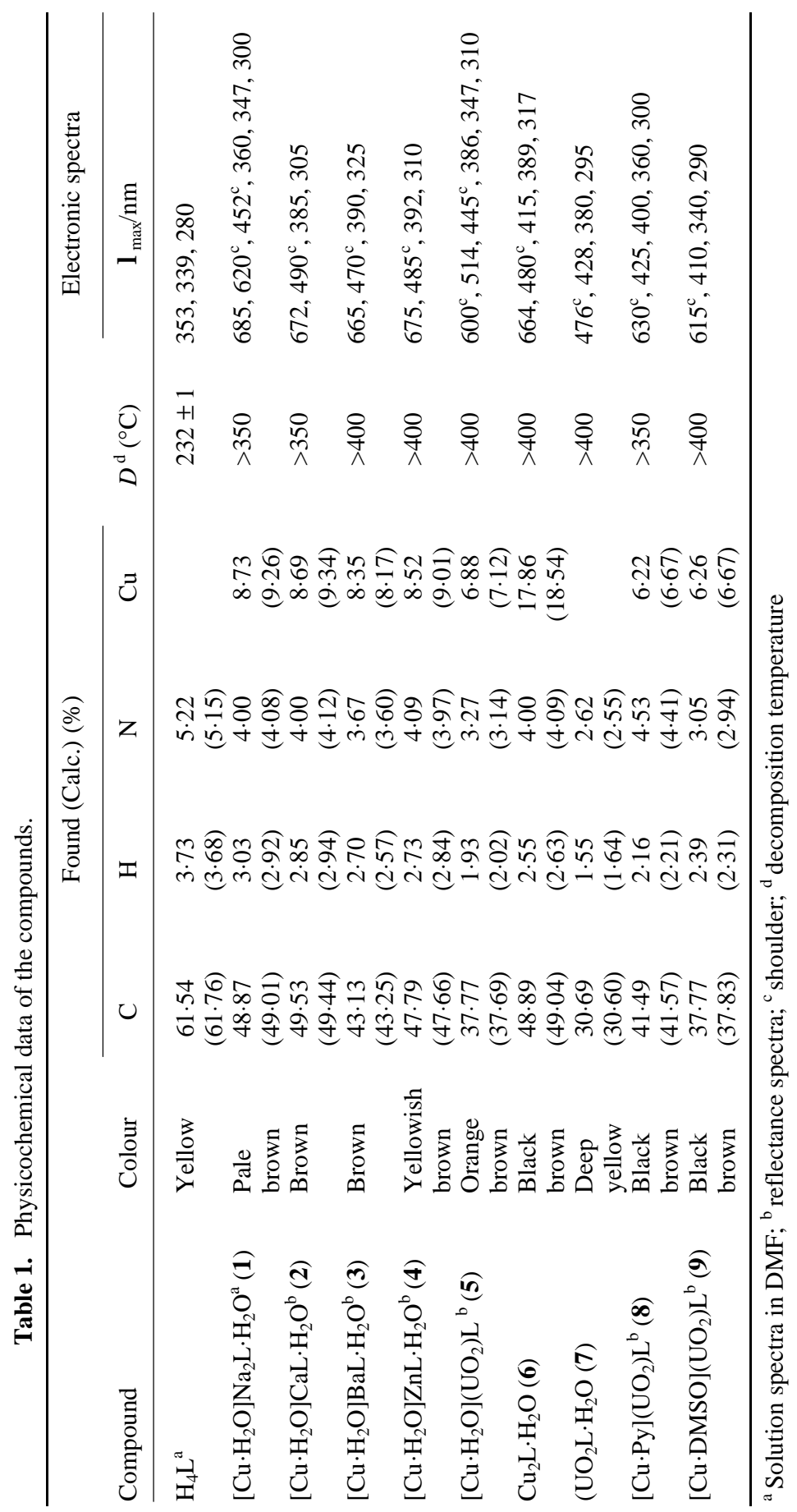




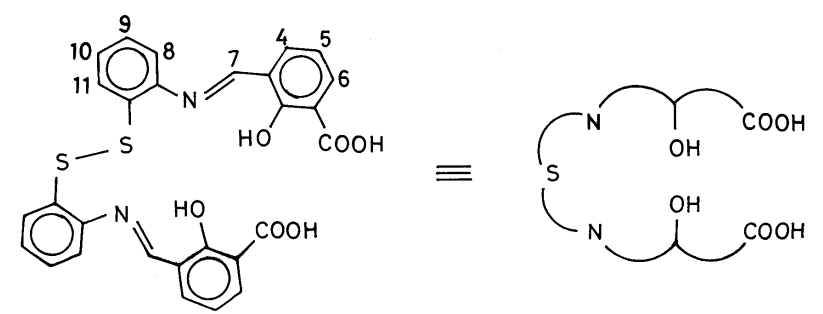

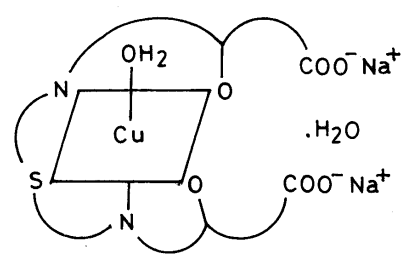

$\left[\mathrm{CuL} \cdot \mathrm{H}_{2} \mathrm{O}\right] \mathrm{Na}_{2} \cdot \mathrm{H}_{2} \mathrm{O},(1)$

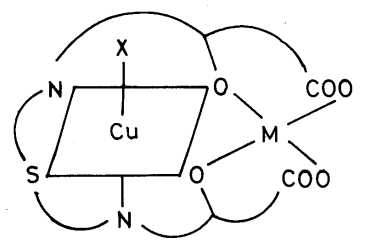

$\mathrm{M}=\mathrm{Zn}^{2+}(\underline{4}), \mathrm{UO}_{2}(\mathrm{VI})(\underline{5}), \mathrm{Cu}^{2+}(\underline{6})$

$X=\mathrm{H}_{2} \mathrm{O}$ for $\underline{4}-\underline{6}$;

$M=\mathrm{UO}_{2}(\mathrm{VI})$ and $\mathrm{X}=\mathrm{Py}(\underline{8}), \mathrm{DMSO}(q)$

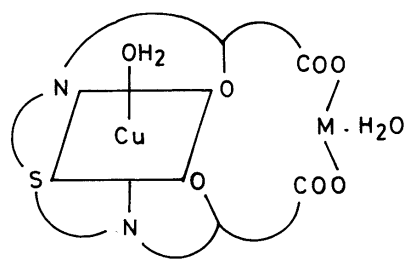

[CuL. $\mathrm{H}_{2} \mathrm{O}$ ].M. $\mathrm{H}_{2} \mathrm{O}$ $\mathrm{M}=\mathrm{Ca}^{2+}(\underline{2}), \mathrm{Ba}^{2+}(\underline{3})$

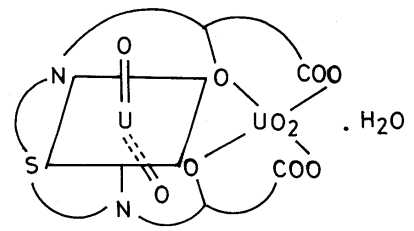

$\left(\mathrm{UO}_{2}\right)_{2}$ L. $\mathrm{H}_{2} \mathrm{O}(7)$

Scheme 1.

\subsection{Spectral studies}

IR spectrum of the ligand exhibits stretching at $1705 \mathrm{~cm}^{-1}$ corresponding to $v(\mathrm{COOH})$. A broad vibration band at $\approx 3200 \mathrm{~cm}^{-1}$ is assigned to $\mathrm{v}(\mathrm{OH})^{21}$ and $\mathrm{v}(\mathrm{C}-\mathrm{O})$ (phenolic) is observed at $1510 \mathrm{~cm}^{-1}$. The sharp intense band at $760 \mathrm{~cm}^{-1}$ is referred to $v(\mathrm{C}-\mathrm{S})^{22}$ and the band at $1630 \mathrm{~cm}^{-1}$ is assigned to $v(\mathrm{C}=\mathrm{N})$. The ligand structure is established by ${ }^{1} \mathrm{H}-\mathrm{NMR}$ data. The spectrum was taken in DMSO- $d_{6}$. The protons were assigned on the basis of spin-spin interaction and comparing with the previously reported results ${ }^{19}$. The singlet at the furthest downfield position is assigned to $\delta(\mathrm{OH})$ (phenolic), 11.07 ppm followed by a signal at $9.70 \mathrm{ppm}$ (singlet) for $\delta(\mathrm{CH}=\mathrm{N})$. Other protons are designated as follows: $4-\mathrm{H}$, $8 \cdot 15 d(8 \cdot 5) ; 5-\mathrm{H}, 7 \cdot 12 t(9.0) ; 6-\mathrm{H}, 8.30 d(8.5) ; 8-\mathrm{H}, 7 \cdot 43 d(8.0) ; 9,10-\mathrm{H}, 7 \cdot 20 m$ and $11-\mathrm{H}$, $7.00 d(8.0) \mathrm{ppm}(d=$ doublet; $t=$ triplet, $m=$ multiplet, the coupling constant $(J, \mathrm{~Hz})$ is given in parentheses). The $\delta(\mathrm{COOH})$ does not appear and may be due to proton exchange with very small amounts of moisture in DMSO- $d_{6}$.

The complexes (1-7) exhibit broad medium bands centred at $3440 \mathrm{~cm}^{-1}$ corresponding to coordinated water. Complex 1 exhibits medium intense bands at 1590 
and $1360 \mathrm{~cm}^{-1}$ corresponding to $v_{a s}(\mathrm{COO})$ and $v_{s}(\mathrm{COO})$. There is substantial change in the position of $\mathrm{v}_{a s}(\mathrm{COO})$ in other complexes; it is shifted to lower energies by $15-40 \mathrm{~cm}^{-1}$ from that of $\mathbf{1}$, which is a diagnostic feature for the formation of dinuclear complexes ${ }^{23}$. Differences in anti-symmetric and symmetric $-\mathrm{COO}^{-1}$ vibrations $(\Delta \mathrm{v})$ are $>200 \mathrm{~cm}^{-1}$ in the complexes, indicating monodentate binding of the $-\mathrm{COO}$ function ${ }^{23}$. The $v(\mathrm{C}=\mathrm{N})$ in the complexes appears at $1615-1620 \mathrm{~cm}^{-1}$ (table 2) and is red-shifted by $5-10 \mathrm{~cm}^{-1}$ from that of the free ligand value. This supports $\mathrm{N}$-coordination to the metal centre ${ }^{15,16}$. The $v(C-S)$ mode of the ligand is shifted to higher energies by $30-50 \mathrm{~cm}^{-1}$ in the complexes indicating M-S linkage ${ }^{15,19}$. The $v\left(\mathrm{C}-\mathrm{O}\right.$ ) (phenolic) occur at $1540-1545 \mathrm{~cm}^{-1}$ in $\mathbf{1 - 3}$ and appear at higher frequencies compared to the free ligand value by $30-35 \mathrm{~cm}^{-1}$. This is in agreement with the phenolato-O single-bonded to the metal ion. In the complexes 4-9, the $v(\mathrm{C}-\mathrm{O})$ (phenolic) appears at $1560-1580 \mathrm{~cm}^{-1}$ and is blue-shifted by $50-70 \mathrm{~cm}^{-1}$ from that of $\mathrm{H}_{4} \mathrm{~L}$. On comparing with the literature report ${ }^{24}$, we assume that the greater shifting of the infrared frequency of the $v(\mathrm{C}-\mathrm{O})$ (phenolic), may be due to the phenolato$\mathrm{O}$ bridging the two metal centres. These observations support the structure of the complexes as given in scheme 1 . Uranyl complexes $(\mathbf{5}, \mathbf{7 - 9})$ display a very strong band at $910-930 \mathrm{~cm}^{-1}$ corresponding to $\mathrm{v}(\mathrm{O}=\mathrm{U}=\mathrm{O})$ modes. The force constant $\left(f_{\mathrm{U}-\mathrm{O}}\right)$ for the $\mathrm{U}=\mathrm{O}$ bond has been calculated according to the published method ${ }^{25}$ and the values obtained (7.00-7.45 mdynes/Å) agree well with those of similar uranyl complexes ${ }^{22}$. The $f_{\mathrm{U}-\mathrm{O}}$ value in each case was used to calculate the $\mathrm{U}=\mathrm{O}$ bond length using Jones' formula ${ }^{25}$ and the values obtained $(1.72-1.73 \AA)$ are in the expected range $(1.69-1.92 \AA)^{22}$. $\left(\mathrm{UO}_{2}\right)_{2} \mathrm{~L} \cdot \mathrm{H}_{2} \mathrm{O}$ shows stretching at the highest frequency of $930 \mathrm{~cm}^{-1}$, which may be due to the decreased tendency to transfer charge from the bridging oxygen to the uranium on coordination to the second metal ion ${ }^{1-3}$. In $[\mathrm{Cu} \cdot \mathrm{DMSO}]\left(\mathrm{UO}_{2}\right) \mathrm{L}(\mathbf{8}), \mathrm{v}(\mathrm{S}=\mathrm{O})$ appears at $980 \mathrm{~cm}^{-1}$ supporting $>\mathrm{S}=\mathrm{O} \rightarrow \mathrm{UO}_{2}$ coordination ${ }^{26}$.

Because of the sparing solubility of $\mathrm{H}_{4} \mathrm{~L}$ in common organic solvents, the solution electronic spectrum was taken in DMF solution. $\left[\mathrm{Cu} \cdot \mathrm{H}_{2} \mathrm{O}\right] \mathrm{Na}_{2} \mathrm{~L} \cdot \mathrm{H}_{2} \mathrm{O}(\mathbf{1})$ is sufficiently soluble in DMF while other complexes remain sufficiently insoluble to measure solution electronic spectra and their diffused reflectance spectra were taken. The spectral data are

Table 2. Infrared ${ }^{\mathrm{a}}$, magnetic moment and ESR data.

\begin{tabular}{|c|c|c|c|c|c|c|c|c|c|c|}
\hline \multirow[b]{3}{*}{ Compound } & \multicolumn{7}{|c|}{ IR data $\left(\mathrm{cm}^{-1}\right)$} & & \multirow{2}{*}{\multicolumn{2}{|c|}{ ESR data }} \\
\hline & \multirow[b]{2}{*}{$v\left(\mathrm{H}_{2} \mathrm{O}\right)$} & \multirow[b]{2}{*}{$\mathrm{v}_{\mathrm{as}}(\mathrm{COO})$} & \multirow[b]{2}{*}{$v(C=N)$} & \multirow{2}{*}{$v(\mathrm{C}-\mathrm{S})$} & \multirow{2}{*}{$\begin{array}{c}\mathrm{v}(\mathrm{C}-\mathrm{O}) \\
(\text { phenolic })\end{array}$} & \multirow[b]{2}{*}{$v\left(\mathrm{UO}_{2}\right)$} & \multirow{2}{*}{\multicolumn{2}{|c|}{$v(\mathrm{M}-\mathrm{S}) \mu(\mathrm{BM})$}} & & \\
\hline & & & & & & & & & $g_{\|}$ & $g_{\perp}$ \\
\hline $\mathrm{H}_{4} \mathrm{~L}^{\mathrm{a}}$ & $3200^{\mathrm{b}}$ & 1705 & 1630 & 760 & 1510 & & & & & \\
\hline 1 & 3450 & 1590 & 1620 & 790 & 1545 & & 325 & $1 \cdot 84$ & $2 \cdot 26$ & $2 \cdot 10$ \\
\hline 2 & 3420 & 1575 & 1620 & 795 & 1540 & & 320 & 1.85 & $2 \cdot 24$ & $2 \cdot 08$ \\
\hline 3 & 3400 & 1575 & 1618 & 795 & 1540 & & 325 & $1 \cdot 86$ & $2 \cdot 22$ & $2 \cdot 10$ \\
\hline 4 & 3420 & 1568 & 1617 & 810 & 1570 & & 325 & 1.75 & $2 \cdot 20$ & $2 \cdot 08$ \\
\hline 5 & 3450 & 1555 & 1620 & 800 & 1565 & 920 & 330 & $1 \cdot 80$ & $2 \cdot 20$ & $2 \cdot 10$ \\
\hline 6 & 3430 & 1550 & 1615 & 800 & 1580 & & 335 & 0.80 & $\mathrm{e}$ & $\mathrm{e}$ \\
\hline 7 & 3400 & 1555 & 1625 & 800 & 1565 & 930 & 330 & & & \\
\hline 8 & - & 1560 & 1620 & 800 & 1570 & 910 & 325 & 1.72 & $2 \cdot 19$ & 2.08 \\
\hline 9 & - & 1560 & 1620 & 800 & 1570 & 910 & 325 & 1.74 & $2 \cdot 18$ & 2.09 \\
\hline
\end{tabular}

${ }^{\mathrm{a}} \mathrm{KBr}$ disk; ${ }^{\mathrm{b}} \mathrm{v}(\mathrm{O}-\mathrm{H}) ;{ }^{\mathrm{c}}$ polycrystalline state at $77 \mathrm{~K} ;{ }^{\mathrm{d}} \mathrm{v}(\mathrm{S}=\mathrm{O}), 980 \mathrm{~cm}^{-1} ;{ }^{\mathrm{e}}$ six-line ESR spectrum 
collected in table 1. The solution of $\mathrm{H}_{4} \mathrm{~L}$ shows two successive transitions at 353 and $339 \mathrm{~nm}$ and refer to intraligand charge transfer transitions. Bluish-brown solution of $\mathbf{1}$ in DMF shows a broad band centred at $685 \mathrm{~nm}$ and a shoulder at $620 \mathrm{~nm}$ along with a weak band at $425 \mathrm{~nm}$. The reflectance spectra of (2-6) exhibit broad absorption bands in the range $665-675 \mathrm{~nm}$ and weak bands at $470-490 \mathrm{~nm}$. The former are assigned to $d-d$ transitions and the latter to $\mathrm{S} \rightarrow \mathrm{Cu}$ (II) charge transitions ${ }^{27}$. All the complexes show strong transitions in the range $375-390 \mathrm{~nm}$ assigned to intraligand charge transitions.

\subsection{Magnetic studies}

Magnetic susceptibility measurements at $300 \mathrm{~K}$ exhibit $1 \mathrm{e}$ paramagnetic moment of mono-copper(II) derivatives 1-5, 8, 9. The magnetic moments (1.7-1.8 BM) deviated slightly from the spin only values. The homo-dinuclear copper(II) complex, $\mathrm{Cu}_{2} \mathrm{~L} \cdot \mathrm{H}_{2} \mathrm{O}$ (6) shows very low magnetic moment, 0.80 BM per copper centre. The subnormal magnetic moment indicates that the copper centres are strongly anti-ferromagnetically coupled $^{1-3,8-10,28-30}$. This is not present in monocopper derivatives $(\mathbf{1 - 5}, \mathbf{8}, \mathbf{9})$ and is obviously due to the absence of unpaired spin in the second metal ions of the complexes. The origin of high anti-ferromagnetic interaction in $\mathrm{Cu}_{2} \mathrm{~L} \cdot \mathrm{H}_{2} \mathrm{O}(6)$ may be due to the presence of sulphur coordination ${ }^{29}$. $\left(\mathrm{UO}_{2}\right)_{2} \mathrm{~L} \cdot \mathrm{H}_{2} \mathrm{O}(7)$ is diamagnetic as expected.

The ESR spectra of the complexes (except 7) in polycrystalline state exhibit broad signals which are attributable to dipolar broadening and enhanced spin-lattice

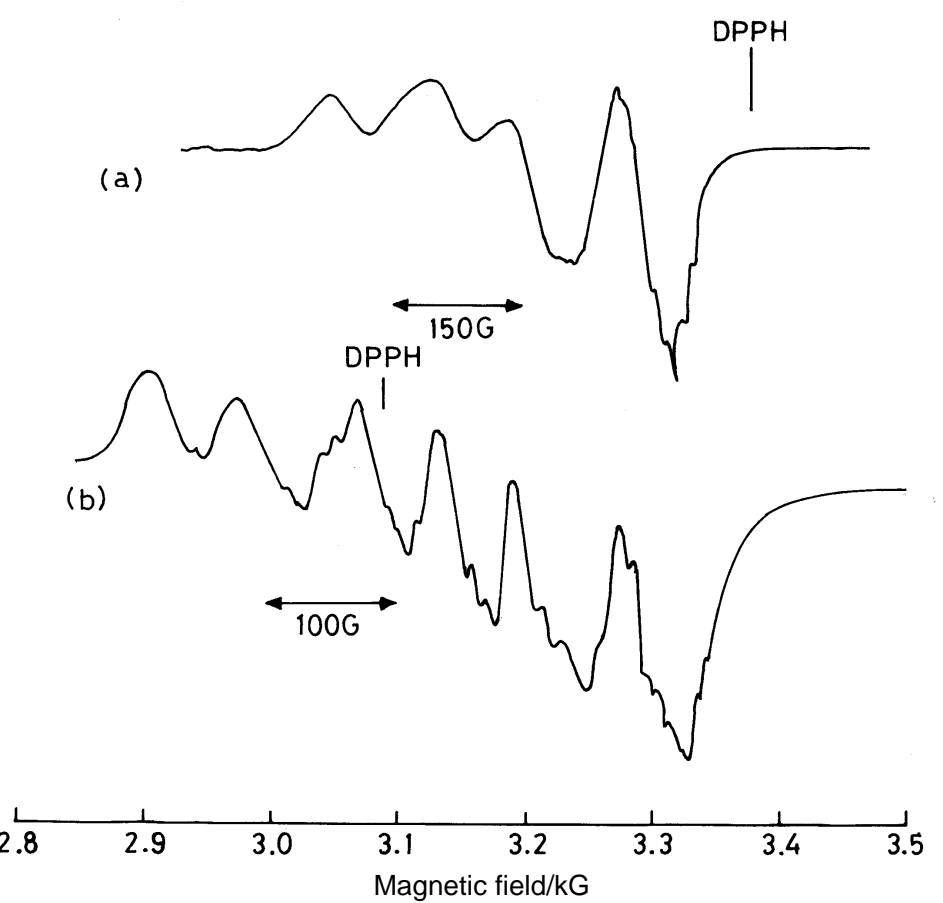

Figure 1. Solid-state ESR spectra of (a) $[\mathrm{Cu}] \mathrm{Na}_{2} \mathrm{~L} \cdot 2 \mathrm{H}_{2} \mathrm{O}$, and (b) $\mathrm{Cu}_{2} \mathrm{~L} \cdot \mathrm{H}_{2} \mathrm{O}$ at $77 \mathrm{~K}$. 
relaxation ${ }^{31}$. The anisotropic spectra are recorded for these complexes at liquid nitrogen temperature and the representative spectra are given in figure 1a. The spectra are anisotropic at high field and the three peaks of low intensity in the weaker field region are taken as originating from $g_{\|} \cdot g_{\|}$and $g_{\perp}$ are computed from the spectra using DPPH free radicals as $g$ markers and these data are collected in table 2 . The data reveal that $g_{\|}>g_{\perp}>2.0$ and $A_{\|}=120 \times 10^{-4} \mathrm{~cm}^{-1}$. This observation suggests a distorted octahedral geometry around $\mathrm{Cu}$ (II) centre ${ }^{32}$. The distortion may originate largely due to the thioether binding to the copper centre. This is supported by the strong preference of thioether to the copper ion when it is part of the ligand to form a five-membered chelate ring in which the other donors are $\mathrm{N}$ or $\mathrm{O}^{33} \cdot \mathrm{Cu}_{2} \mathrm{~L} \cdot 2 \mathrm{H}_{2} \mathrm{O}(6)$ shows six-line X-band ESR spectrum at liquid nitrogen temperature in the polycrystalline state. The spectrum is shown in figure $1 \mathrm{~b}$. In principle, a seven-line $(2 \times(3 / 2) \times 2+1)$ hyperfine ESR spectrum is observable in an ideal dicopper system with one half $A_{\|}$of the mononuclear species. This is also reflected from the observed data. $A_{\|}$estimated from the spectrum is $75 \times 10^{-4} \mathrm{~cm}^{-1}$. Two copper centres in the complex appear in two different symmetry environments. The inner core copper centre appears in a distorted octahedral environment, $\mathrm{CuN}_{2} \mathrm{SO}_{2}\left(\mathrm{OH}_{2}\right)$ and the outer core copper centre is in a square planar arrangement. It is difficult to assign the spectral region to a particular copper centre. We are able to detect additional weak ESR absorptions at $\sim 1500 \mathrm{G}$ near $g=4$ for a spin coupled $\mathrm{Cu}$ (II)-dimer in 6 which is not observed in the case of monocopper derivatives. Superhyperfine structures are seen at higher fields. These fine structure transitions arise from the interaction of the nuclear spins of the nitrogen ligands $(I=1)$ of the $\mathrm{C}=\mathrm{N}$ with the unpaired electron density on $\mathrm{Cu}(\mathrm{II})$. Five $(2 \times 2 \times 1+1)$ super-hyperfine transitions are observed as usual.

\subsection{Thermal studies}

A thermal study was carried out in air under non-isothermal conditions. The mass loss starts at $110^{\circ} \mathrm{C}$, continues up to $150^{\circ} \mathrm{C}$ and corresponds to two moles of co-ordinated water in complexes 1-4 supporting our formulation, while complexes 5-7 exhibit the loss of one mole of $\mathrm{H}_{2} \mathrm{O}$. In the uranyl complexes $[\mathrm{Cu} \cdot \mathrm{S}]\left(\mathrm{UO}_{2}\right) \mathrm{L}(\mathrm{S}=\mathrm{Py}, \mathrm{DMSO}),(\mathbf{8}, \mathbf{9})$, mass loss starts at high temperatures $\left(200-260^{\circ} \mathrm{C}\right)$. All the complexes finally produce their oxides as residue on heating at $500-800^{\circ} \mathrm{C}$, but their compositions have not been determined.

\subsection{Electrochemical studies}

Redox properties of monocopper(II) complexes were examined by cyclic voltammetry in DMF solution using glassy carbon milli-electrodes. The potentials are expressed with reference to SCE. Complexes exhibit $\mathrm{Cu}^{\mathrm{II}} \rightarrow \mathrm{Cu}^{\text {III }}$ oxidation ${ }^{34}$ and $\mathrm{Cu}^{\mathrm{II}} \rightarrow \mathrm{Cu}^{\mathrm{I}}$ reduction ${ }^{34}$. The potentials (V) are as follows: 1, $0 \cdot 20$ (140), 2, 0.23 (160), 3, 0.27 (160), 4, 0.33 (140), 5, 0.49 (145), and the respective reduction potentials are: -0.612 (160), $-0.803(150),-0.854(180),-0.868(170)$ and -0.893 (170) (values in parentheses represent peak-to-peak separation, $\Delta E_{p}=E_{p a}-E_{p c}$ ). Thus, the redox processes are quasireversible in nature. Because of the insolubility of the dicopper complexes electrochemical activities could not be determined. 


\section{Conclusions}

Condensation of 3-formylsalicylic acid and bis-(2-aminophenyl)disulphide has yielded a new type of septadentate compartmental Schiff base. It forms oxo-bridged binuclear complexes of inner $\mathrm{N}_{2} \mathrm{SO}_{2}$ and outer $\mathrm{O}_{2} \mathrm{O}_{2}$ coordination type. Hetero-dinuclear complexes with copper(II) at the inner compartment and calcium(II), barium(II), zinc(II), dioxouranium(VI) at the outer compartment are synthesised and characterized by IR, electronic/reflectance spectroscopy, ESR and magnetic moment measurements. These complexes exhibit $\mathrm{Cu}^{\mathrm{II}} \rightarrow \mathrm{Cu}^{\mathrm{III}}$ oxidation and $\mathrm{Cu}^{\mathrm{II}} \rightarrow \mathrm{Cu}^{\mathrm{I}}$ reduction reaction at cyclic voltammetric time scale. Homo-dinuclear complexes of copper(II) and dioxouranium(VI) are also synthesised and characterised by spectral and magnetic studies. The dicopper(II) complex shows antiferromagnetic coupling.

\section{Acknowledgements}

Financial support received from the University Grants Commission, New Delhi, is gratefully acknowledged. One of us (JKN) thanks Dr S Chattopadhyay of Vidyasagar University, Midnapur for his encouragement and helpful discussions.

\section{References}

1. Zanello P, Tamburini S, Vigato P A and Mazzocchin G A 1987 Coord. Chem. Rev. 77165

2. Guerriero P, Tamburini S and Vigato P A 1995 Coord. Chem. Rev. 13917

3. Alexander V 1995 Chem. Rev. 95273

4. Costes J P, Daham F, Dupuis A and Laurent J-P 1997 Inorg. Chem. 363429

5. Aguian A, Tamburini S, Tomasin P and Vigato PA 1997 Inorg. Chim. Acta 256199

6. Furutachi H and Okawa H 1997 Inorg. Chem. 363911

7. Dutta S K, Werner R, Florke U, Mohanta S, Nanda K K, Haase N and Nag K 1996 Inorg. Chem. 352292

8. Dey K and Nandi K K 1996 Indian J. Chem. A35 766

9. Yu J W, Tao R J, Zhou X Y, Jui D M and Liao D 1994 Polyhedron 13951

10. Lam F, Wang R J, Mak T C W and Chan K S 1994 J. Chem. Soc., Chem. Commun. 2439

11. Casellato U, Guerriero P, Tamburini S and Vigato P A 1990 J. Chem. Soc., Dalton Trans. 1533

12. Karlin K D and Zubieta J (eds) 1982 Copper coordination chemistry: Biological and inorganic perspective (Guiderland: Adenine Press)

13. Kahn O, Galy J, Journaux Y, Jaud J and Badaran I M 1982 J. Am. Chem. Soc. 1042165

14. Carrillo D 1992 Coord. Chem. Rev. 119137

15. Chattopadhyay P and Sinha C 1996 Indian J. Chem. A35 523

16. Vogel A I 1959 A text book of practical organic chemistry 3rd edn (London: Longman) p. 169

17. Duff J C and Bills E J 1934 J. Chem. Soc. 1305

18. Nag J K, Das D, De B B and Sinha C 1998 J. Indian Chem. Soc. 75496

19. Vogel A I 1975 A text book of quantitative inorganic analysis 3rd edn (London: Longman) p. 358

20. Karmakar S, Chowdhury S B, Ray D and Chakravorty A 1993 Polyhedron 12291

21. Syamal A, Kumar D and Ahmad A 1982 Indian J. Chem. A21 634

22. Deacon G B and Phillips R J 1980 Coord. Chem. Rev. 33227

23. Dey K, Biswas A K and Sinha Roy A 1981 Indian J. Chem. 20848

24. Jones L H 1959 Spectrochim. Acta 15409

25. Davies A J 1981 Adv. Inorg. Chem. Radio Chem. 24115

26. Sivagnanam U and Palaninandavar M 1994 J. Chem. Soc., Dalton Trans. 2277

27. Korupoju S R and Zacharias P S 1996 Indian J. Chem. A35 1104 
28. Benzekri A, Dubourdeaux P, Latour J M, Rey P and Laugier J 1991 J. Chem. Soc., Dalton Trans. 3359

29. Khan O, Mallah T, Gouteron J, Jeanin S and Jeanin Y 1989 J. Chem. Soc., Dalton Trans. 1117

30. Crowford van H and Hatfield William E 1977 Inorg. Chem. 161336

31. Malachowski M R, Huynh H B, Tomlinson L J, Kelly R S and Furbeejun J W 1995 J. Chem. Soc., Dalton Trans. 31

32. Toscano P J, Fordon K J, Macherone D, Liu S and Zubieta J 1990 Polyhedron 92375

33. McAuley A, Subramanian S and Zaworotko M J 1999 Inorg. Chem. 385078

34. Zhang W, Liu S, Ma C and Jiang D 1998 Polyhedron 173835 